\title{
Application of D-STATCOM for Harmonic Reduction using Power Balance Theory
}

\author{
Mohd. Navaid Ansari ${ }^{a}$, Rishi Kumar Singh ${ }^{\text {b }}$
}

${ }^{a}$ Ph.D. Scholar, Electrical Engineering Department, Maulana Azad National Institute of Technology, Bhopal, India

${ }^{\mathrm{b}}$ Assistant Professor, Electrical Engineering Department, Maulana Azad National Institute of Technology, Bhopal, India

\begin{abstract}
In modern power systems due to prolific use of non-linear devices harmonics are present in the distribution system. To reduce the harmonics and source neutral current D-FACT along with a star-delta transformer and Power Filter is proposed in shunt. In this article, the three phase load has been taken from NTS Industries, which deals with FMCG products. This system includes 3 phase 3 wire system having industrial load such as mixer grinder, pulverizer, packaging machine, etc. A star-delta transformer along with three leg voltage source inverter and a capacitor used to filter out harmonics present in supply current. Power balance theory is used to control the D-FACT. A MATLAB Simulink model was created and the results were discussed.
\end{abstract}

Keywords: Total Harmonic Distortion,Power Filter,D-STATCOM, Star-delta Transformer.

\section{Introduction}

The use of non-linear devices in the domestic as well as industrial appliances has directly increase the amount of harmonics in the power supply. Earlier, the problem was rectified by passive power filters in the power system with use of capacitors and inductors. This method was of least cost however, affect significantly the load and system impedance characteristics. Also the compensation was provided steeply i.e. fixed conditions, component size was large, and could produce resonance condition. Now-a-days FACTS devices took place of passive filter and possess effective compensation for reactive power, current harmonics as well as power factor correction [1-15]. Chandan Kumar et al in [2] proposed instantaneous symmetric component theory for controlling active power filter, in [3] PV-DSTATCOM is proposed using adaptive reweighted zero attracting control algorithm. And many more control strategy are available in literature.

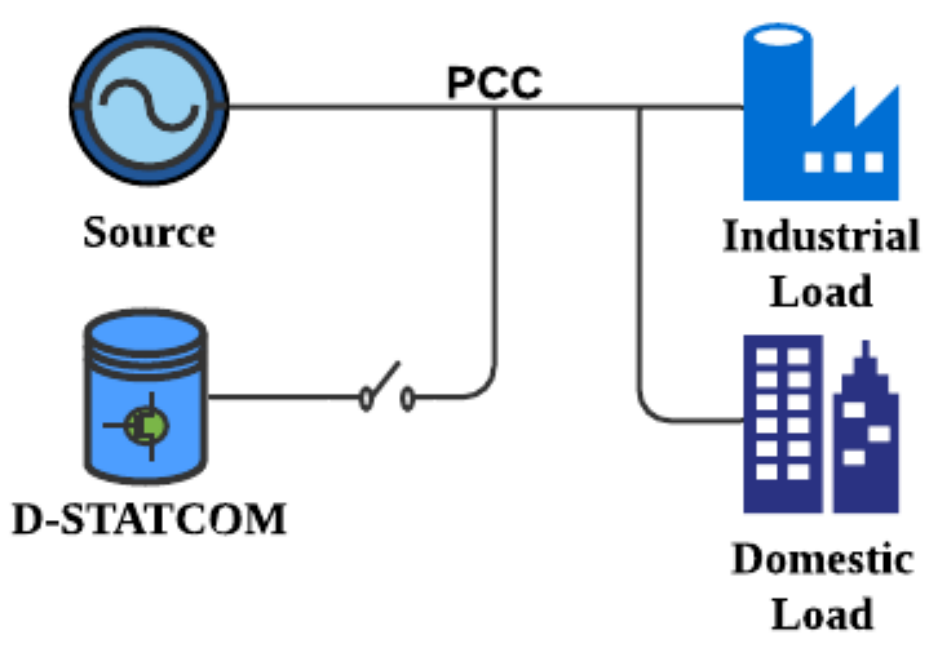

Figure.1 system configuration

\section{Distribution Static Compensator}

It consist of coupling inductance, VSC (Voltage Source Converter) and a capacitor connected at the point of common coupling where three phase source and non-linear load is connected. The active power filter generates the desired amount of current to cancel out the harmonics present in the current. And supplies that generated current to load. And hence the source current regains the ideal condition that is sinusoidal nature. With the suitable control the D-FACT can also compensate the power factor of load. 


\section{MATLAB Model of System Configuration}

Three phase AC supply is supplying three phase reactive unbalanced non-linear load, at PCC a D-FACT and star-delta transformer are connected, a single phase power filter is connected across a switch which is connected between neutral wire of source and neutral wire of star-delta transformer. That means when the switch is closed power filter is bypassed and when the switch is opened power filter comes in to operation.

\section{Working of Proposed System}

Due to the unbalance in system and non-linear devices there exist neutral current and harmonics in the power system. To eliminate the harmonics D-STATCOM as a D-FACTS device is connected which take care of positive and negative sequence component. Star delta transformer has low impedance route for zero sequence component of current. Power filter generates the required amount of neutral current and supply to load through star-delta transformer winding. Which results the harmonics and neutral current from source eliminated. Simulation of complete system has been designed on MATLAB 2015.

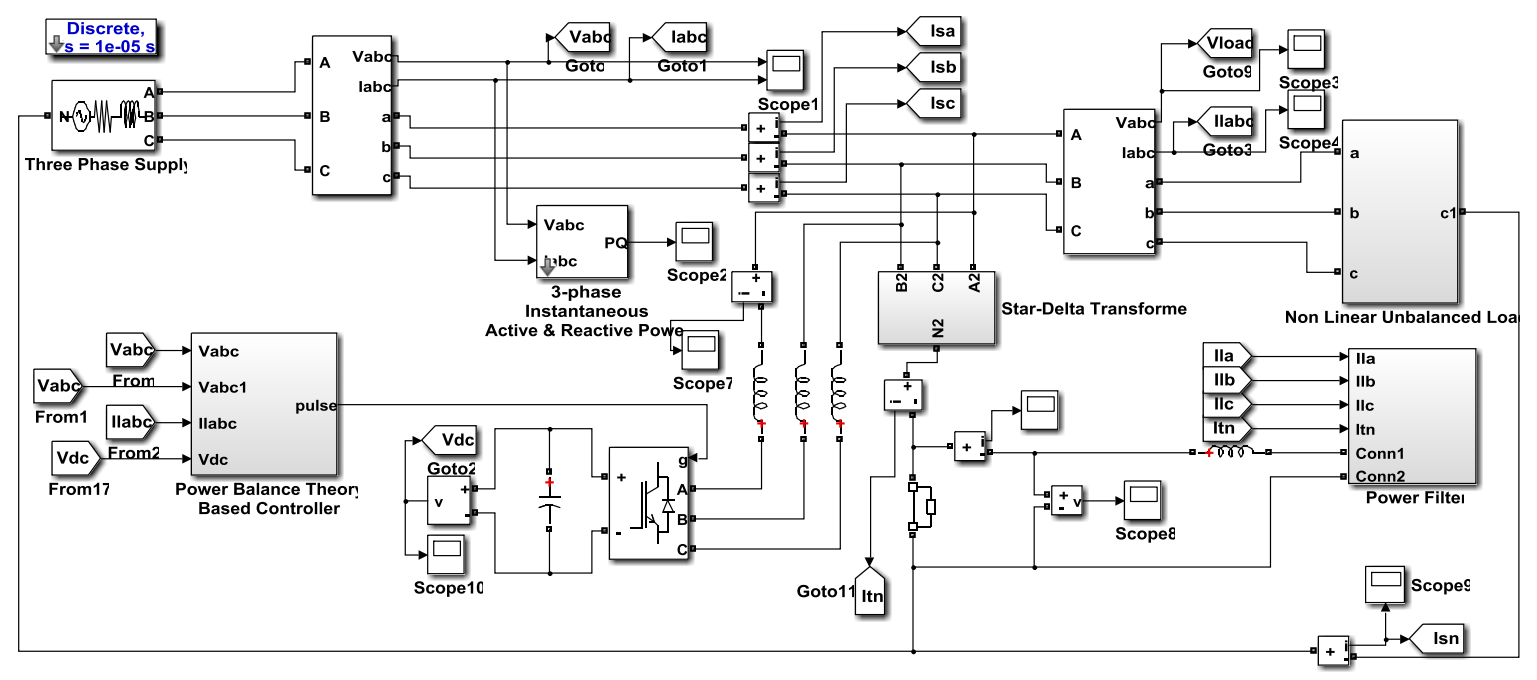

Figure.2 MATLAB model for system configuration

\section{Power Balance Theory}

There are many solutions available for generation of gate pattern for VSC of D-STATCOM [1-10]. In this article PBT is used for generation of firing pulse for D-STATCOM. The block diagram for PBT is shown in Fig. 3. PBT requires quadrature vector and in-phase vector to generate source current reference. The basic equation for elimination of harmonics present in current are given as follows

- $\quad$ Reference source current in-phase component

The amplitude of supply voltage VRYB $\left(v_{r}, v_{y}, v_{b}\right)$ considered sinusoidal at PCC is computed as:

$$
V_{t}=\left\{2 / 3\left(v_{r}^{2}+v_{y}^{2}+v_{b}^{2}\right)\right\}^{1 / 2}
$$

The instantaneous value of the unity amplitude models is in phase with the instantaneous supply voltage, can be derived as:

$$
U_{s r p}=v_{r} / V_{t} ; U_{s y p}=v_{y} / V_{t} ; U_{s b p}=v_{b} / V_{t}
$$

- Evaluation of active power proportion and generation of in-phase reference current

The load current's instantaneous active power is calculated as 


$$
\begin{gathered}
V_{L}=\left(i_{L r} v_{r}+i_{L y} v_{y}+i_{L b} v_{b}\right) \\
P_{L}=P_{L D C}+P_{A C_{\text {oscillating }}}
\end{gathered}
$$

Since instantaneous power is a mixture of both oscillating and non-oscillating component, a low pass filter is used to isolate the non-oscillating portion of load power.

The amplitude of the load current's fundamental active power portion is calculated as:

$$
I_{s m p}^{*}=(2 / 3) P_{L} / V_{S}
$$

The difference in voltage between the reference capacitor voltage and the sensed capacitors voltage of DSTATCOM is fed into a PI controller, whose output is represented by $I_{s m d}^{*}$.

$$
I_{s m d(n)}^{*}=K_{p} V_{d c e}+K_{i d} \int V_{d c e} d t
$$

Where DC bus PI voltage controller has $K_{p}$ proportional gain and $K_{i d}$ integral gain constants. So reference supply current's active component is:

$$
I_{s m}^{*}=I_{s m p}^{*}+I_{s m d}^{*}
$$

Reference supply current's three phase active power portion are:

$$
I_{s r p}^{*}=I_{s m}^{*} \times U_{s r p} ; I_{s y p}^{*}=I_{s m}^{*} \times U_{s y p} ; I_{s b p}^{*}=I_{s m}^{*} \times U_{s b p}
$$



Figure.3 Block diagram of power balance theory

- Evaluation of quadrature and reactive power component generation

The unit vector templates are $90^{\circ}$ phase shift with quadrature components can be obtained as:

$$
\begin{gathered}
U_{s r q}=\left(-U_{s y p}+U_{s b p}\right) / \sqrt{3} \\
U_{s y q}=\left(\sqrt{3} U_{s r p}+U_{s y p}-U_{s b p}\right) / \sqrt{2} \sqrt{3}
\end{gathered}
$$




$$
U_{s b q}=\left(-\sqrt{3} U_{s r p}+U_{s y p}-U_{s b p}\right) / \sqrt{2} \sqrt{3}
$$

In the same way, another PI controller is used to control the terminal voltage. The terminal voltage amplitude is determined by equation (1) and the reference value is given to PI controller.

To maintain AC terminal voltage constant. The output of PI controller is given as:

$$
I_{s n a}^{*}=K_{p a} V_{a c e}+K_{i a} \int V_{a c e} d t
$$

The load has instantaneous reactive power:

$$
Q_{L}=(1 / \sqrt{3})\left\{\left(v_{r}-v_{y}\right) i_{L r}+\left(v_{y}-v_{b}\right) i_{L y}+\left(v_{b}-v_{r}\right) i_{L b}\right\}
$$

$Q_{L}$ is the combination of oscillating and non-oscillating components, so low pass filter is used to extract load reactive power. The load current has reactive power fundamental component given by:

$$
I_{s n q}^{*}=(2 / 3) Q_{L} / V_{S}
$$

The amplitude of reference supply current's reactive power portion is:

$$
I_{s n}^{*}=I_{s n a}^{*}-I_{s n q}^{*}
$$

Reference supply current's quadrature components are:

$$
I_{s r q}^{*}=I_{s n}^{*} U_{s r q} ; I_{s y q}^{*}=I_{s n}^{*} U_{s y q} ; I_{s b q}^{*}=I_{s n}^{*} U_{s b q}
$$

- Reference Supply Current

The sum of quadrature and in-phase components of reference supply current gives the total 3-phase reference current:

$$
I_{s r}^{*}=I_{s r p}^{*}+I_{s r q}^{*} ; I_{s y}^{*}=I_{s y p}^{*}+I_{s y q}^{*} ; I_{s b}^{*}=I_{s b p}^{*}-I_{s b q}^{*}
$$

These obtained reference supply currents are compared with sensed supply current and the error between two is given to hysteresis based controller to produce the 6- gate pulse for IGBT's of D-STATCOM.

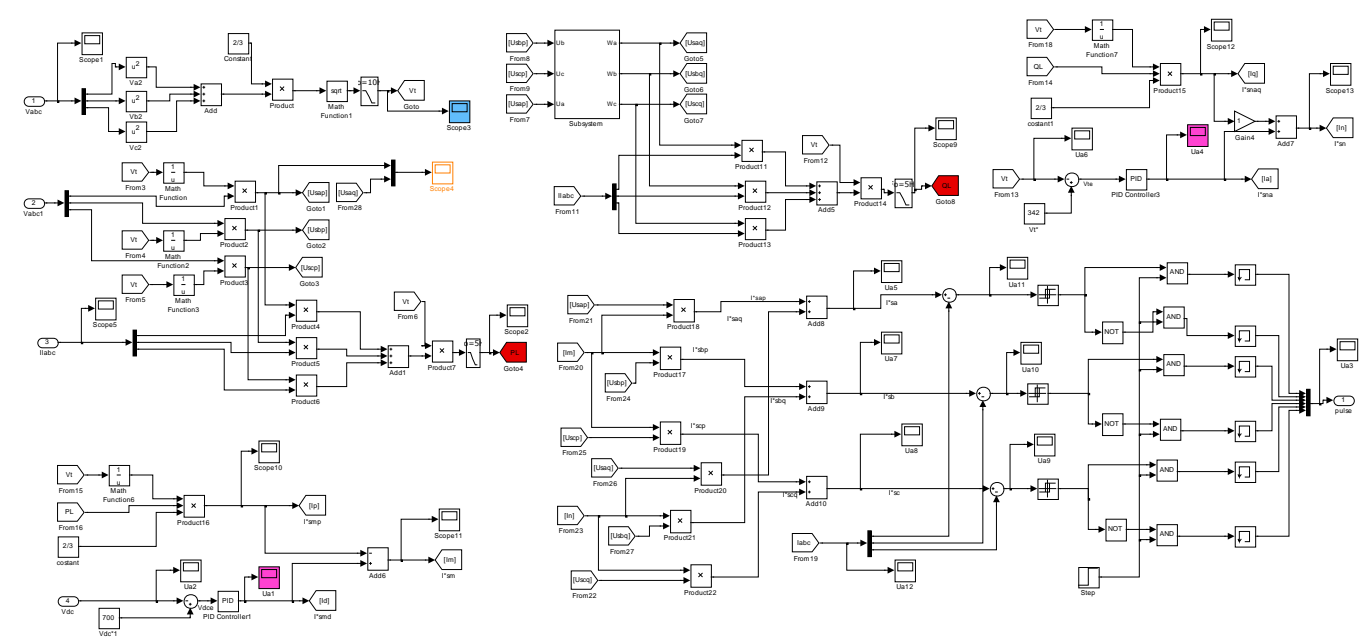

Figure.4 Mathematical modelling of power balance theory in MATLAB 


\section{Control of Power Filter}

Power filter is connected between neutral wire of transformer and load. A separate single phase AC source is used to energize the capacitor. The three phase load current is compared with neutral current of transformer and passed through PID controller which gives the error which is then compared to carrier wave to generate gate pulse as shown in Fig. 5.The population includes prospective teachers of Tirunelveli District.

\section{Simulation Results and Discussion}

Simulation result are shown in fig. 6. Where different output are shown on the scope of MATLAB. Where first output waveform shows the 3-phase supply voltage, second shows the 3-phase supply current, third shows the neutral current of source, fourth shows the voltage across the capacitor of D-FACT and fifth shows the transformer neutral current.

A small proportion of the gate pulse generated by using power balance theory is shown in fig. 9. The complete time line of simulation and the effect of compensation on THD is shown in fig. 10.

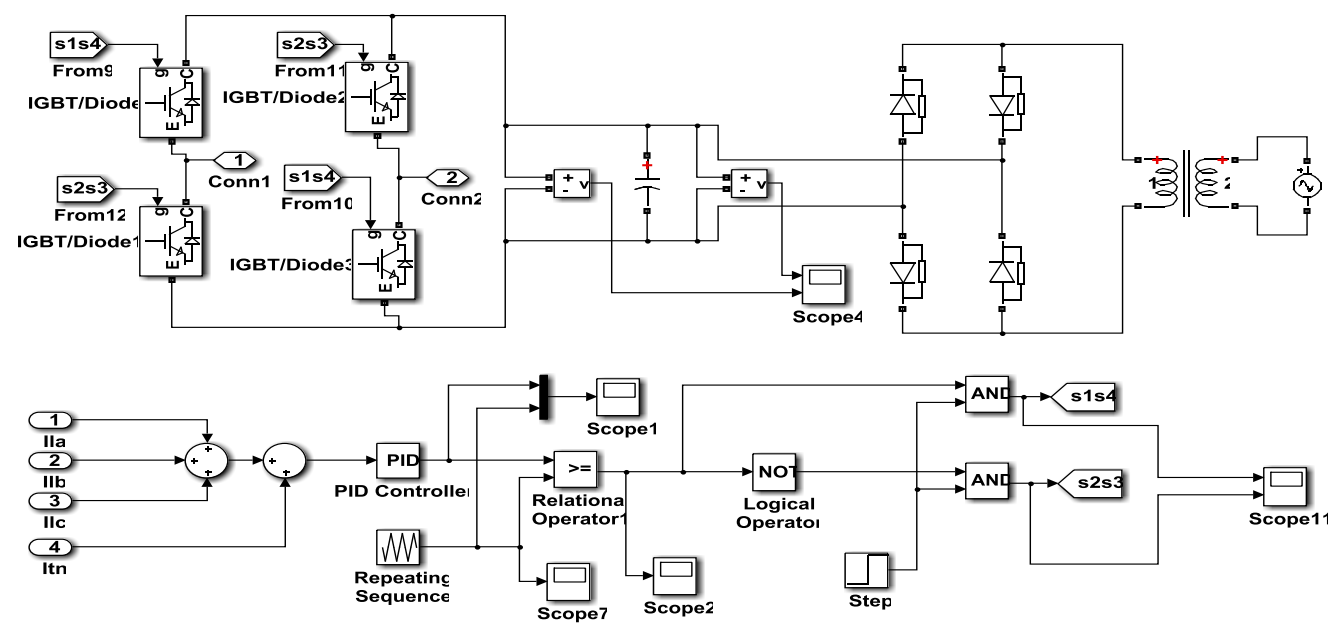

Figure.5 Control method of power filter

Table 1. Parameters used in simulation

\begin{tabular}{|l|l|}
\hline Simulation Parameters & Values \\
\hline AC Source & 415 Volts VL-L, 50 Hz \\
\hline Source Impedance & $\mathrm{R}=0.1$ ohms and L $=0.001 \mathrm{H}$ \\
\hline Capacitor DC & $4400 \mu \mathrm{F}, 700 \mathrm{~V}$ \\
\hline Star-delta transformer & $\mathrm{A} 3$-phase two winding transformer \\
& $\frac{V_{L}}{\sqrt{3}}: \frac{V_{L}}{\sqrt{3}}(240 / 240$ Volts $)$ \\
\hline Induction motor & $250 \mathrm{~V}, 2880 \mathrm{RPM}$, Single Phase 2 H.P. \\
\hline Coupling Inductor & $\mathrm{L}=2.5 \mathrm{mH}$ \\
\hline Switching frequency of PWM & $10 \mathrm{kHz}$ \\
\hline
\end{tabular}



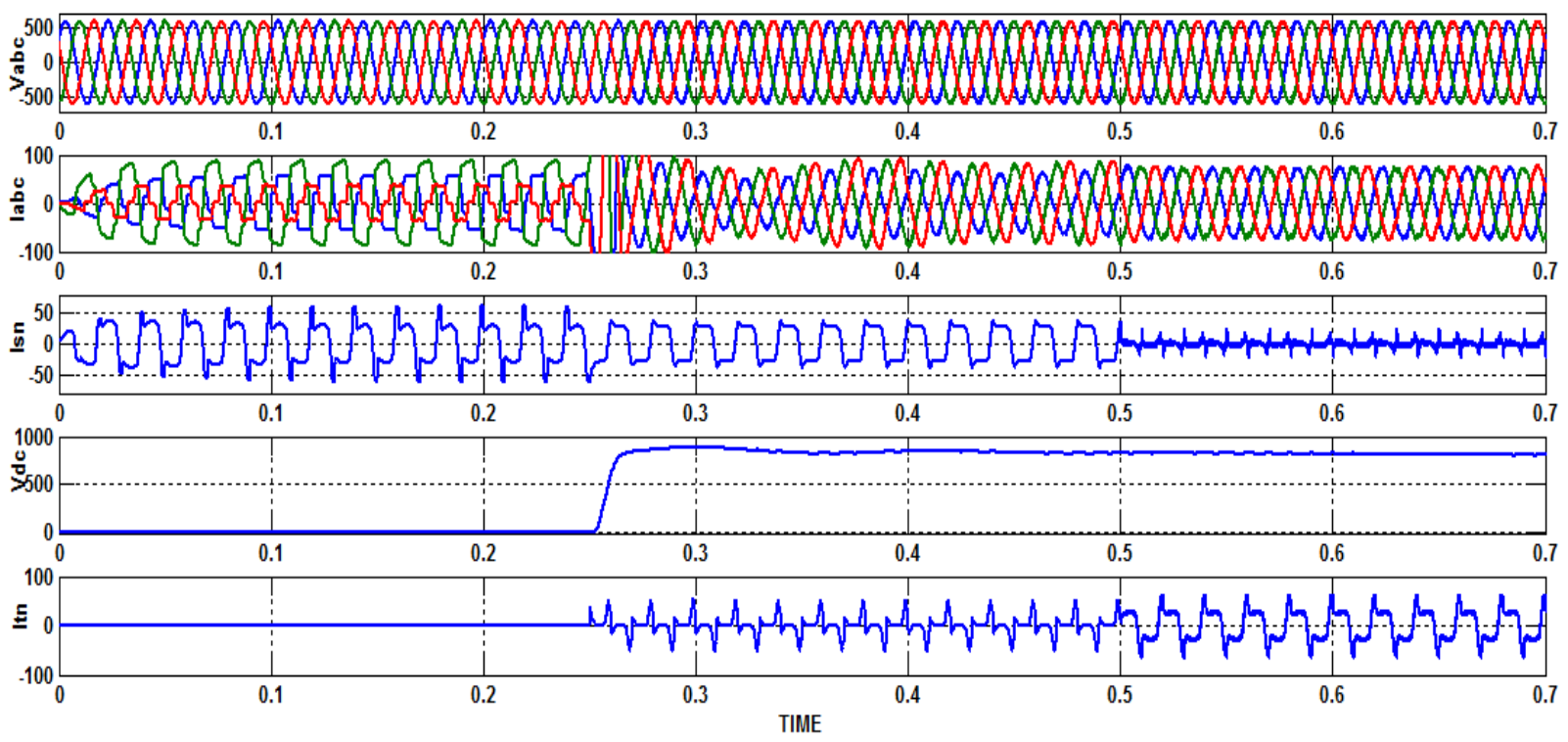

Figure.6 Performance analysis of D-STATCOM with star-delta transformer and power filter.
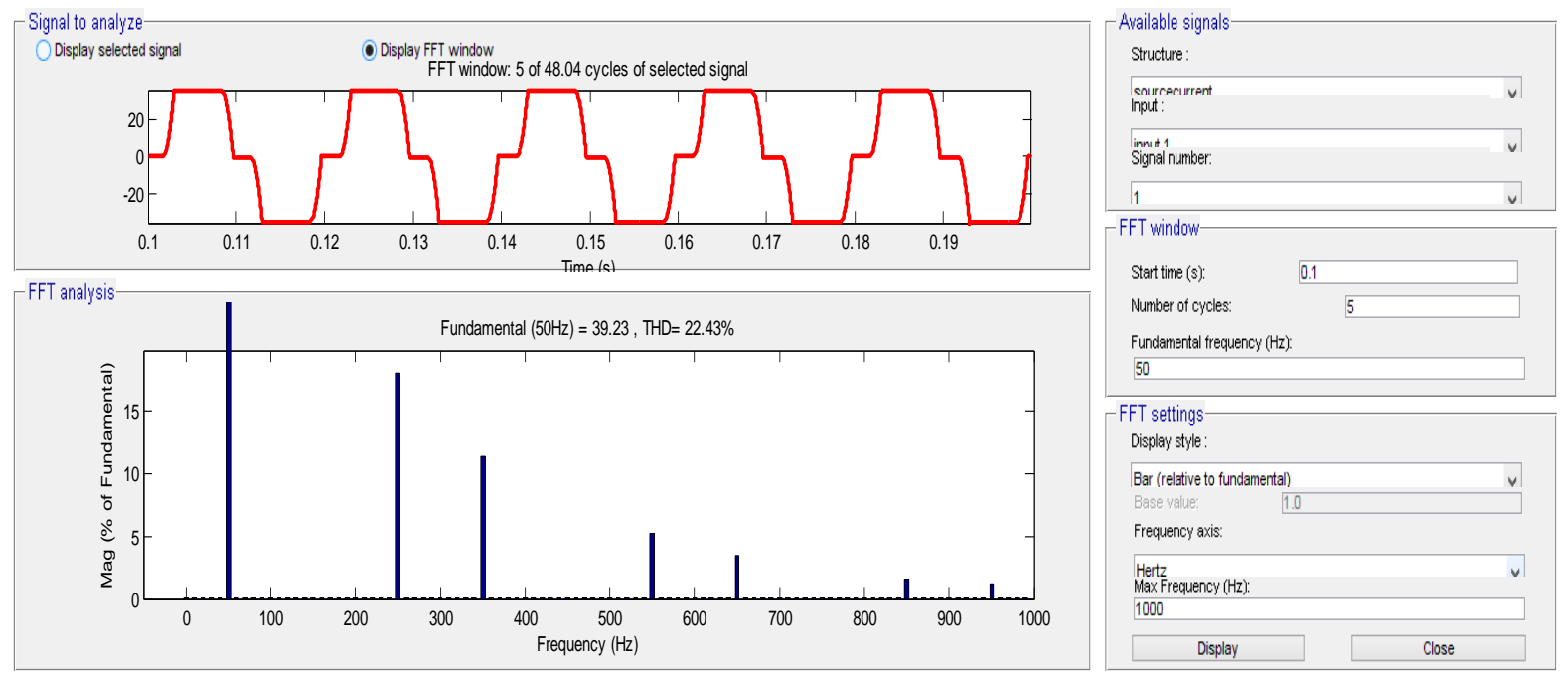

Figure.7 THD of supply current without compensating device
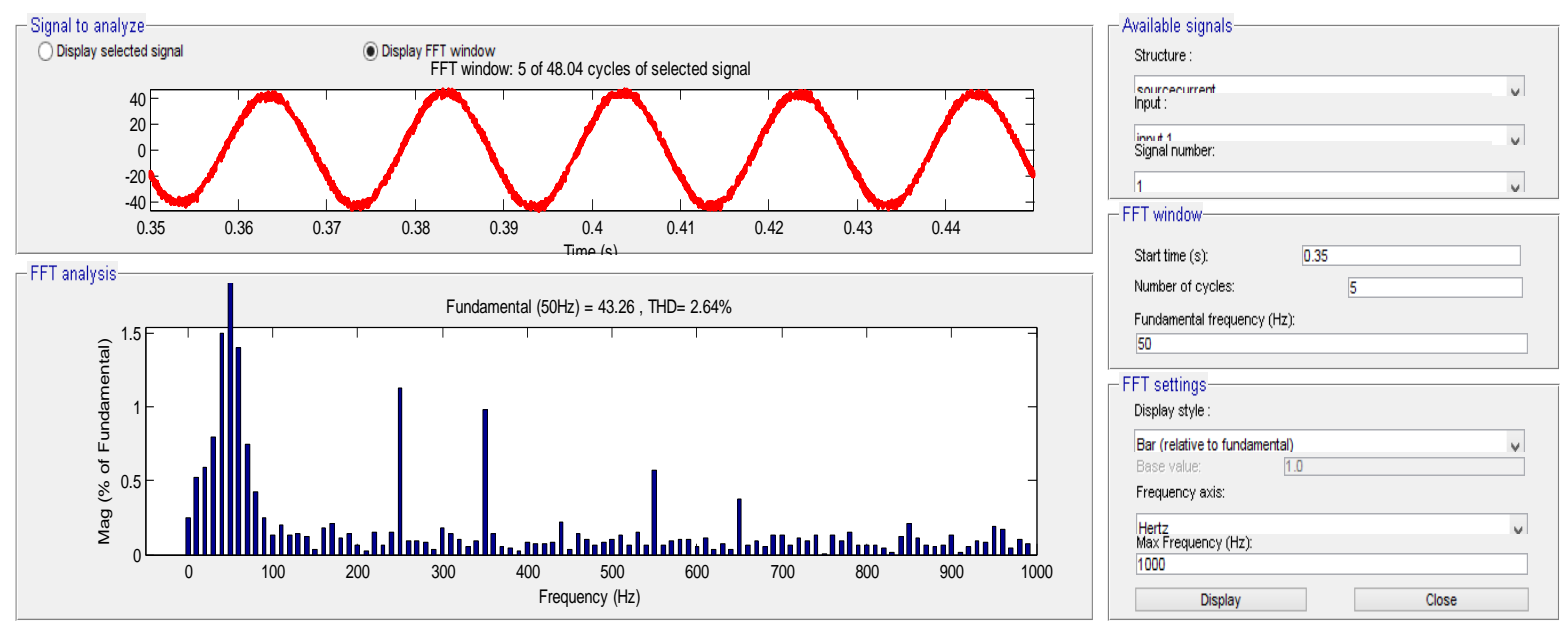

Figure.8 THD of supply current with compensating device 


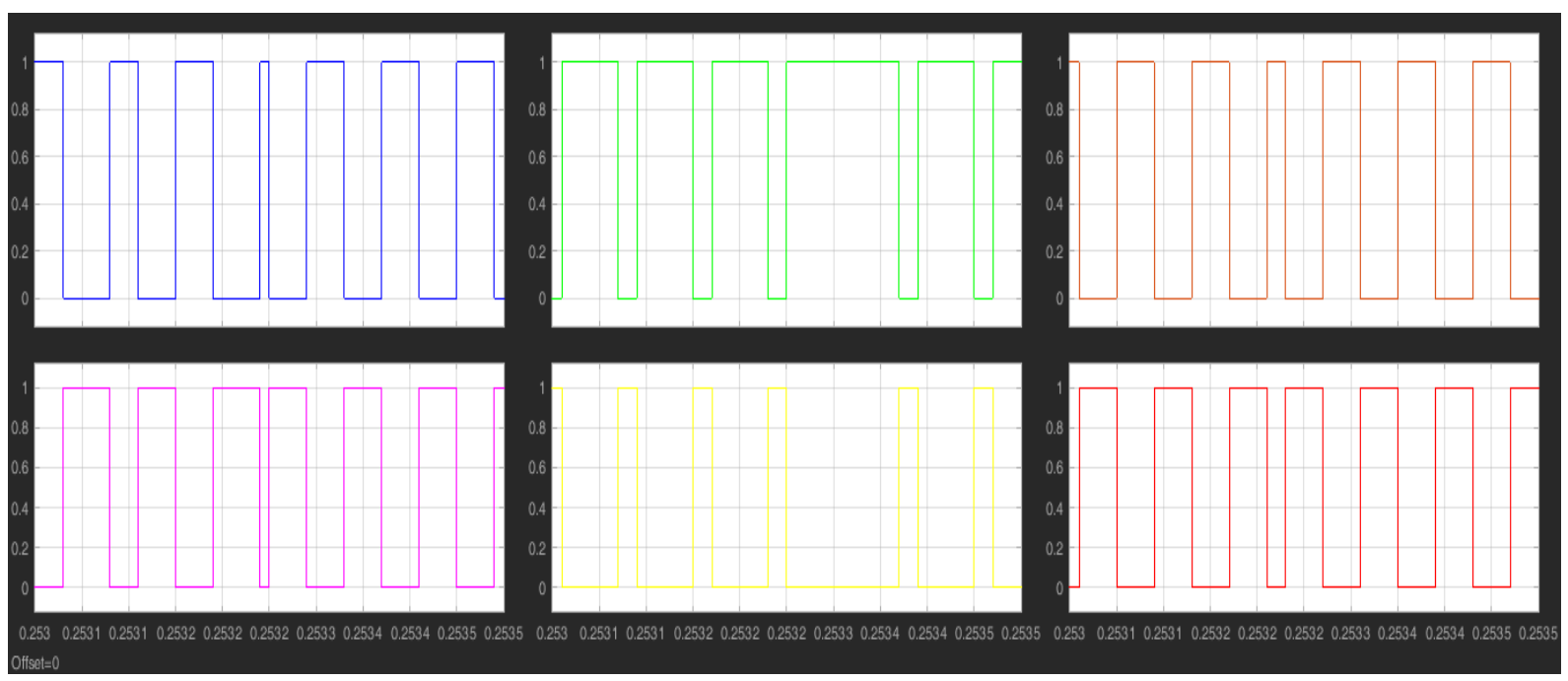

Figure.9 Gate pulse generation of IGBT switch of D-STATCOM

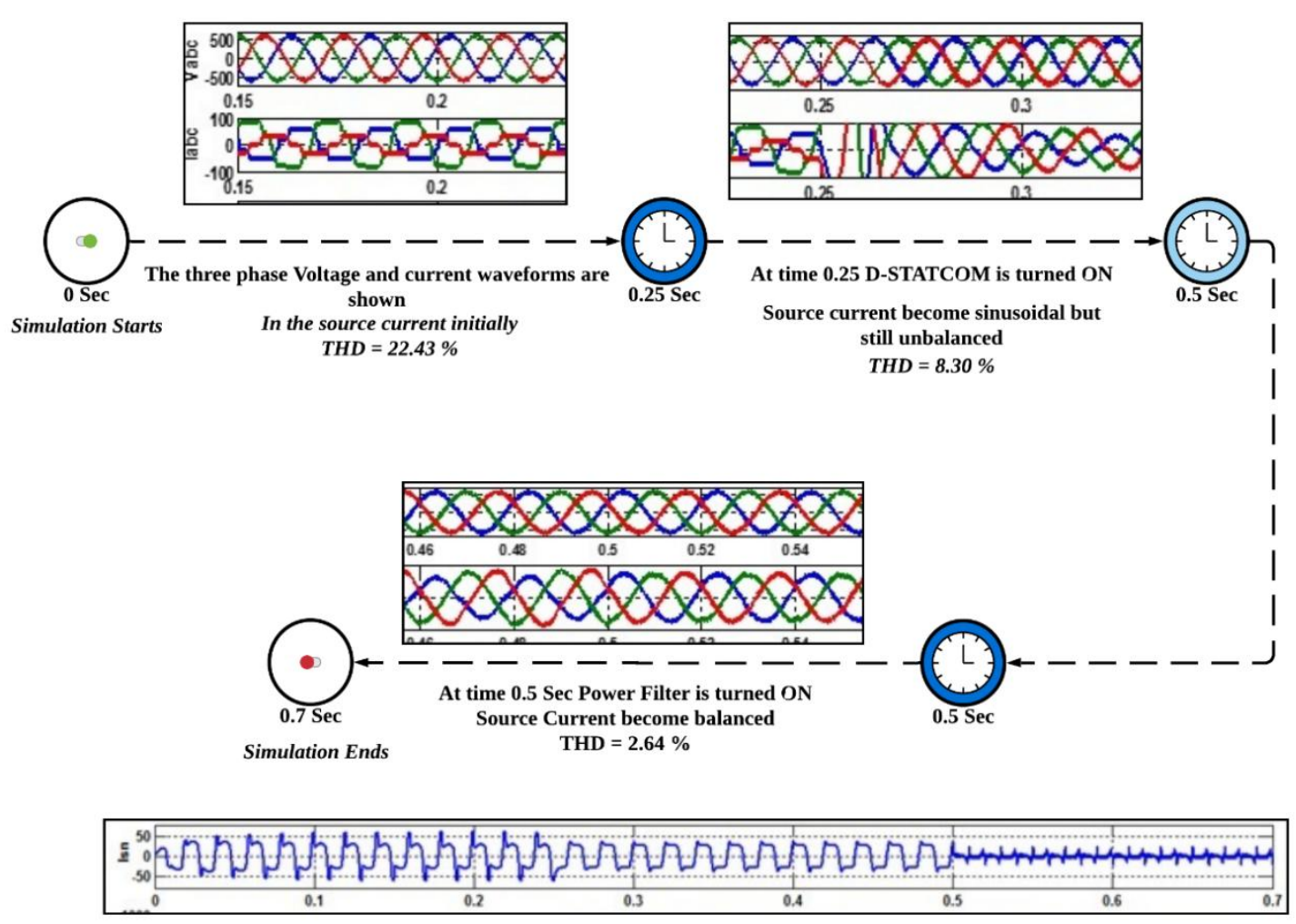

Source Neutral Current $\left(\mathrm{I}_{\mathrm{S}_{n}}\right)$ from starting to end of simulation

Initially without compensation $I_{S n}$ around $28 \mathrm{Amp}$ rms, When D-STATCOM is turned $O N I_{S n}$ falls around 17.32 Amps, at $0.5 \mathrm{Sec}$ when power filter is turned on $\mathrm{I}_{\mathrm{Sn}}$ further reduced to $2.88 \mathrm{Amps}$.

Figure.10 Time line for simulation results

\section{Conclusion}

In this article a power balanced theory is implemented to extract the gate signals for the voltage source inverter used as active power filter. It can be concluded that THD obtained after compensation is $2.64 \%$ which is well within the limit of IEEE 519 standards. Also with the help of power filter and star-delta transformer neutral 
current of source also reduced to great extent. The simulated results shows that the THD before and after compensation. And the results are satisfactory lies in IEEE standards.

\section{References}

1. B. Singh, A Chandra, and K. Al-Haddad, Power quality: problems and mitigation techniques. John Wiley \& Sons, 2014.

2. Chandan Kumar, et al (2020). A new voltage control strategy to improve performance of DSTATCOM in electric grid, CES Transaction on Electrical Machines and Systems, 4(4), 295-302.

3. B. Singh, M. Kandpal, and I. Hussain, (2018). Control of grid tied smart PV-DSTATCOM system using an adaptive technique, IEEE Transaction on Smart Grid, 9(5), 3986-3993.

4. BukolaBabatundeAdetokun, et al (2021). Application and control of flexible alternating current transmission system devices for voltage stability enhancement of renewable-integrated power grid: A comprehensive review, 7.

5. R. Hemalatha, M. Ramasamy, (2020). Microprocessor and PI controller based three phase CHBMLI based DSTATCOM for THD mitigation using hybrid control techniques, Microprocessors and Microsystems, 76.

6. Kumar, M., Swarnkar, A., Gupta, N. and Niazi, K.R. (2017). Design and operation of DSTATCOM for power quality improvement in distribution systems, The Journal of Engineering, 2328-2333.

7. D. Sreenivasarao, Pramod Agarwal and Biswarup Das, (2013). A T-connected transformer based hybrid D-STATCOM for three-phase, four-wire systems, International Journal of Electrical power and Energy System. 44, 964-970.

A. K. Panda, T. Penthia, M. Mangaraj and A. R. Dash, (2018). Power quality refinement by executing icos $\Theta$ Control Algorithm in Fuel Cell based DSTATCOM, IEEMA Engineer Infinite Conference (eTechNxT), 1-6.

8. D. Sreenivasarao, Pramod Agarwal, Biswarup Das, (2013). Performance enhancement of a reduced rating hybrid D-STATCOM for three-phase, four-wire system, Elsevier, International Journal of Electrical power and Energy System, 97, 158-177.

9. Samuel N. Duarte, et al, (2020). Control algorithm for DSTATCOM to compensate consumergenerated negative and zero sequence voltage unbalance, International Journal of Electrical Power \& Energy Systems, 120.

10. Chandankumar, Mahesh K. Mishra, (2014). An Improved Hybrid DSTATCOM Topology to Compensate Reactive and Nonlinear Loads, IEEE Transaction on Industrial Electronics, 61, 65176527.

11. Chandan Kumar, Mahesh K. Mishra, (2014). A Voltage-Controlled DSTATCOM for Power-Quality Improvement, IEEE, Transaction on Power Delivery, 29, 1499-1507.

12. Sabha Raj Arya, Bhim Singh, (2013). Performance of DSTATCOM Using Leaky LMS Control Algorithm, IEEE Journal of Emerging and Selected Topics in Power Electronic, 1, 104-113.

13. Bhim Singh, Sabha Raj Arya, (2013). Adaptive Theory-Based Improved Linear Sinusoidal Tracer Control Algorithm for DSTATCOM, IEEE Transaction on Power Electronics, 28, 3768-3778.

14. Bhim Singh, Jitendra Solanki, (2009). A comparison of control algorithms for DSTATCOM, IEEE Transaction on Industrial Electronics, 56, 2738-2745.

15. P Jayaprakash, Bhim Singh, D P Kothari, (2012). Reduction in Rating of Voltage Source Converter of DSTATCOM using a Zig-Zag Transformer, IEEE International Symposium on Industrial Electrinics, 1066-1071.

16. Gaurav Kumar Kasal, Bhim Singh, (2010). Zig-Zag transformer based voltage controller for an isolated Asynchronous generator, IEEE Conference on TENCON, 1-6.

17. Shweta Singhai, Mohd. Navaid Ansari, Monika Jain, (2016). Application of DSTATCOM for power quality improvement using isolated zig-zag/star transformer under varying consumer load. IEEE International conference on Electric Power and Energy Systems, 270-275. 